\title{
ВЛИЯНИЕ ОСТРОЙ СОМАТИЧЕСКОЙ БОЛИ НА КИЛЛИНГОВУЮ АКТИВНОСТЬ НЕЙТРОФИЛОВ НОВОРОЖДЕННЫХ КРЫС
}

\section{В. В. Алексеев ${ }^{\natural}$, А. Х. Каде ${ }^{2}$}

${ }^{1}$ Ростовский государственный медицинский университет, Ростов-на-Дону, Россия

2 Кубанский государственный медицинский университет, Краснодар, Россия

Иммунная система претерпевает влияния различной природы. Один из факторов, сопровождающих жизнедеятельность организма, — боль. Знать и учитывать возрастные особенности факторов врожденного иммунитета необходимо для адекватной оценки изменения их параметров в онтогенезе. В литературных источниках недостаточно данных об особенностях изменения киллинговой активности нейтросилов в ответ на острую боль у новорожденных. Целью работы было выявить изменения фагоцитарной активности нейтрофилов в ответ на краткосрочный алгогенный стимул у новорожденных крыс. Эксперимент проводили на 3-5-дневных крысятах. Были сформированы две группы: контрольная и экспериментальная с моделированием острого алгогенного воздействия. После моделирования осуществляли забор материала через 2, 30-60, 120-180 мин. Для оценки микробицидной активности нейтрофилов использовали спонтанный и стимулированный методы автоматизированного учета теста с нитросиним тетразолием (НСТ-теста). Сравнение данных проводили на основе U-критерия Манна-Уитни. Наблюдали повышение значений спонтанного НСТ-теста с 50,7 до 58,6 у. ед. через 30-60 мин ( < 0,01), а также стимулированного НСТ-теста с 71,5 до 87,4 у. ед. (p < 0,001) в течение первого часа эксперимента. Максимально выраженное изменение коэфициента микробицидности наблюдали через 2 мин с 1,40 до 1,72 у. ед. (p < 0,001). К концу эксперимента показатели приближались к исходным значениям. При анализе результатов учитывали, что новорожденные крысята испытывают влияние со стороны микробной колонизации, на фоне которой развертывается реакция нейтрофилов на алгогенное раздражение.

Ключевые слова: боль, НСТ-тест, новорожденные, нейтрофилы, микробицидность нейтросилов

Благодарности: В. Г. Овсянникову, заведующему кафедрой патологической физиологии РостГМУ и А. Е. Бойченко, профессору кафедры патологической физиологии за ценные идеи и критические замечания. И. А. Абояну, главному врачу КДЦ «Здоровье» за предоставленную возможность использовать оборудование лаборатории

Вклад авторов: В. В. Алексеев - проведение экспериментальной и аналитической части исследования, анализ и интерпретация данных, написание рукописи; А. Х. Каде - разработка концепции и дизайна, проверка интеллектуального содержания, окончательное редактирование.

Соблюдение этических стандартов: исследование одобрено этическим комитетом РостГМУ (протокол № 20/17 от 23 ноября 2017 г.)

$\bigotimes$ Для корреспонденции: Алексеев Владимир Вячеславович

пер. Нахичеванский, д. 29, г. Ростов-на-Дону, 344022; alexeev911@gmail.com

Статья получена: 17.12.2019 Статья принята к печати: 07.01.2020 Опубликована онлайн: 20.01.2020

DOI: $10.24075 /$ vrgmu.2020.002

\section{THE EFFECT OF ACUTE SOMATIC PAIN ON THE KILLING ACTIVITY OF NEUTROPHILS IN NEWBORN RATS}

Alekseev $\mathrm{W}^{1} \bowtie$, Kade AKh²

${ }^{1}$ Rostov State Medical University, Rostov-on-Don, Russia

${ }^{2}$ Kuban State Medical University, Krasnodar, Russia

The immune system is subject to all sorts of influences. Pain is one of them, accompanying an organism's existence. It is essential to be aware of and account for age-related characteristics of the innate immunity in order to adequately assess their dynamics in ontogenesis. The literature is scarce on the changes to the killing activity of neutrophils occurring in newborns in response to acute pain. The aim of this study was to detect potential changes to the phagocytic activity of neutrophils in response to an algogenic stimulus in newborn rats. The experiments were carried out in 3-5-day-old rats. Two groups were formed: the control group and the main group, in which acute pain was modelled. Blood samples were collected 2, 30-60 and 120-180 minutes after exposure to the algogenic stimulus The microbicidal activity of neutrophils was measured using a spectrophotometric modification of the spontaneous/stimulated nitroblue tetrazolium (NBT) reduction test. The results were compared using the Mann-Whitney $U$ test. In the first hour following pain modeling, the stimulated NBT reduction test demonstrated an increase in the measured parameters from 71.5 to 87.4 a.u. $(p<0.001)$; the spontaneous NBT reduction test showed an increase from 50.7 to 58.6 a.u. $(p<0.01) 30$ to $60 \mathrm{~min}$ after exposure. The most pronounced change of the microbicidal activity coefficient was observed 2 min after pain modeling, increasing from 1.40 to 1.72 a.u $(p<0.001)$. By the end of the experiment, the measured parameters approximated their initial values. During the analysis, we accounted for the fact that the neutrophil response to the algogenic stimulus was unfolding in the setting of microbial colonization occurring in newborns.

Keywords: pain, NBT test, newborns, neutrophils, neutrophil microbicidal activity

Acknowledgements: the authors thank Ovsyannikov VG, Head of the Department of Pathologic Physiology (Rostov State Medical University) and Boychenko AE, Professor at the Department of Pathologic Physiology, for their valuable advice and feedback; Aboyan IA, Chief Physician of the Clinical Diagnostic Center Health, for granting access to the laboratory equipment of the Center.

Author contribution: Alexeev W conducted the experiment, analyzed and interpreted the obtained results, wrote the manuscript; Kade AKh conceived and designed the study, revised the manuscript for intellectual content and made final corrections.

Compliance with ethical standards: the study was approved by the Ethics Committee of Rostov State Medical University (Protocol № 20/17 dated November 23, 2017).

$\triangle$ Correspondence should be addressed: Vladimir V. Alexeev per. Nakhichevansky, 29, Rostov-on-Don, 344022; alexeev911@gmail.com Received: 17.12.2019 Accepted: 07.01.2020 Published online: 20.01.2020 DOI: $10.24075 /$ brsmu.2020.002 
В литературе накоплено большое количество фактов, свидетельствующих о том, что изменение иммунологического механизма реактивности возможно при раздражении неантигенной природы. В частности, при воздействии стресса [1, 2], инфракрасного света [3], светодиодного освещения [4], магнитного поля [5], наркотических веществ [6], тяжелой физической нагрузки [7] и т. д. Боль в этом отношении не должна стать исключением.

Вовлечение нейтрофилов в острый алгогенный процесс у взрослых крыс убедительно показано Н. С. Алексеевой. Наблюдаемая этим автором реакция ярко выражена, но быстро угасает, что дало автору право сформулировать понятие о синдроме функциональной готовности нейтрофилов к эфффективному фагоцитозу на случай, если сценарий долорогенной атаки найдет свое развитие при возможном повреждении тканей, их инфицировании и т. п. [8]

Есть основания полагать, что алгогенное раздражение новорожденных крысят вызовет у них комплекс ответных реакций. В их числе изменение фагоцитарной активности нейтрофилов. Показано, что среди прочих факторов врожденного иммунитета наиболее реагирующими на изменения в среде внутриутробного пребывания и при рождении оказываются нейтрофилы [9].

В доступной литературе нами не было найдено данных о влиянии острой соматической боли на киллинговую активность нейтрофилов новорожденных крыс. Цель работы - выявить изменения фагоцитарной активности нейтросрилов в ответ на краткосрочный алгогенный стимул у новорожденных крыс.

\section{МАТЕРИАЛЫ И МЕТОДЫ}

Объектом исследования были белые новорожденные 3-5-дневные крысята средней массой по 12-14 г. Все экспериментальные животные рождались и росли в стационарных условиях в комфортном температурном режиме (около $24^{\circ} \mathrm{C}$ ). Пол крысят в ходе эксперимента не учитывали. Световой день составлял 12 ч. Эксперименть проводили летом.

Для определения функциональной активности нейтрофилов провели 32 эксперимента. Всех животных разделили на две неравные группы: контрольную $(n=8)$ и экспериментальную ( $n=24)$. В экспериментальной группе моделировали острый болевой синдром путем электрокожного раздражения рецепторной зоны корня хвоста крысы. Он достигал 3-4-й степени интенсивности на основании критериев А. В. Вальдмана и Ю. Н. Васильева в модификации В. Г. Овсянникова в течение 2 мин [10].

После моделирования острой соматической боли животных декапитировали и осуществляли забор крови в центрифужную пробирку с гепарином (100 ЕД/мл) через 2, 30-60, 120-180 мин. Кровь разводили средой Хенкса («ПанЭко»; Россия) в соотношении $1: 2$. Центрифугировали в градиенте плотности фиколл-верографин (1,083 г/мл) в течение 45 мин при 1500 об./мин. Для оценки микробицидной активности нейтрофилов использовали спонтанный и стимулированный метод автоматизированного учета теста с нитросиним тетразолием (НСТ-теста) с выделенной клеточной взвесью [11]. Метод основан на способности практически бесцветного НСТ восстанавливаться кислородными радикалами в темно-синий диформазан.

Во все ряды вносили 0,5\%-й раствор НСТ по 50 мкл. В четные ряды планшета добавляли по 50 мкл забусеренного физиологического раствора $(\mathrm{pH}=7,0)$ - при спонтанном НСТ-тесте. В нечетные ряды планшета вносили по 50 мкл
0,1\% латексного раствора с диаметром частиц 1,5 мкм («ПанЭко»; Россия) - при стимулированном НСТ-тесте. Затем планшет инкубировали в термостате 24 мин при $37^{\circ} \mathrm{C}$. Учет результатов производили на спектросротометре Multiscan Sky (THERMO FISHER SCIENTIFIC; CШA) при длине волны 540 нм. Определяли среднюю оптическую плотность в двух лунках спонтанного НСТ-теста и в двух лунках стмулированного. Результаты выражали в условных единицах (1 у. ед. = 1000 ед. оптической плотности). Затем вычисляли коэффициент микробицидности (КМ), разделив среднюю оптическую плотность в стимулированных лунках на среднюю оптическую плотность в лунках без стимуляции.

Статистическую обработку данных проводили с помощью пакетов программ Microsoft Office Excel 2010 Pro (Microsoft; CШA), STATISTICA 10.0 (Statsoft; CШA). Она включала в себя: проверку нормальности распределения количественных признаков с использованием критерия Колмогорова-Смирнова с поправкой Лиллиесорса и критерия Шапиро-Уилка; вычисление медианы (Ме), квантилей $\left(Q_{0,25}\right.$ - нижний, $Q_{0,75}$ - верхний), интервала значений отминимального значения (Min) до максимального (Max) для данных, не подчиняющихся нормальному распределению; сравнение данных на основе U-критерия Манна-Уитни. Критическое значение уровня значимости (p) принимали равным 0,05. Результаты расчетов представлены как медиана с квантилями и интервалом значений Me $\left[\mathrm{Q}_{0,25} ; \mathrm{Q}_{0,75}\right]$ (Min-Max).

\section{РЕЗУЛЬТАТЫ ИССЛЕДОВАНИЯ}

У новорожденных крысят контрольной группы Ме сп нст 50,7 у. ед. $\left[Q_{0,25}=49,3\right.$ у. ед.; $Q_{0,75}=52,7$ у. ед.], $\stackrel{\text { сп ніт }}{\text { Ніn }}$ 48,9 у. ед., Мах - 57,1 у.ед. Через 2 мин после алгогенного воздействия $\mathrm{Me}_{\text {спнст }}=51,4$ у. ед. $\left[\mathrm{Q}_{0,25}=48,8\right.$ у. ед.; $\mathrm{Q}_{0,75}=$ 54,1 у. ед.], Min - 41,9 у. ед., Max - 59,1 у. ед. В течении первого часа эксперимента Ме сп нст $=58,6$ у. ед. $\left[\mathrm{Q}_{0,25}=\right.$ 57,0 у. ед.; $Q_{0,75}=60,5$ у. ед.], $M i n-52,1$ у. ед., $M a x-61,3$ у. ед. В рамках третьего часа наблюдения $\mathrm{Me}_{\text {сп нст }}=46,9$ у. ед. $\left[Q_{0,25}=43,3\right.$ у. ед.; $Q_{0,75}=49,8$ у. ед.], $\operatorname{Min}-41,6$ у. ед.; Мax - 51,1 у. ед.

Как показал статистический анализ, после алгогенного воздействия спонтанный НСТ-тест приходит в движение. Вектор его изменения направлен в сторону активации. Статистически значимые различия по отношению к контролю и первичной реакции зарегистрированы через 30-60 мин от начала эксперимента ( $p<0,01)$. При этом медианные значения результатов свидетельствуют о равномерном распределении показателей между нижним и верхним квантилями, а верхний квантиль приближен к максимальным значениям в выборке. Следует отметить, что наблюдаемая реакция не стойкая, непродолжительна и быстро истощаема. Через 2 ч после болевого воздействия медианные значения спонтанного НСТ-теста становились ниже, чем у животных контрольной группы $(p=0,05)$ (рис. 1).

Контрольные значения стимулированного НСТ-теста выше, чем спонтанного. Ме ст нст $=71,5$ у. ед. $\left[Q_{0,25}=\right.$ 68,0 у. ед.; $Q_{0,75}=73,4$ у. ед.], Min — 67,2 у. ед., Max-76,5 y. ед.

Сразу после нанесения алгогенного стимула все показатели стимулированного НСТ-теста возрастали, что свидетельствует о высокой функциональной готовности нейтрофилов новорожденных крыс к противостоянию возможной микробной атаке. Ме ст нст $=90,4$ у. ед. $(p<0,001)\left[Q_{0,25}=87,8\right.$ у. ед.; $Q_{0,75}=93,0$ y. ед.], $M i n-84,8$ y. ед., Мax - 96,3 у. ед. 
Высокая микробицидная активность сохранялась в течение часа после болевой стимуляции. $\mathrm{Me}_{\text {ст нст }}=87,4$ у. ед. $(p<0,001)\left[Q_{0,25}=78,8\right.$ у. ед.; $Q_{0,75}=89,9$ у. ед.], Min 77,6 у. ед., Мах - 93,0 у. ед.

Как и при постановке спонтанного НСТ-теста, через 2 ч было отмечено истощение резервов микробицидности. Me ${ }_{\text {ст нст }}=64,5$ у. ед. $(0<0,05)\left[Q_{0,25}=57,2\right.$ у. ед.; $Q_{0,75}=$ 66,9 у. ед.], Min - 54,8 у. ед., Max - 74,1 у. ед. (рис. 2).

Признавая, что НСТ-тест отражает метаболическую активность нейтрофилов, кислородзависимые механизмы их микробицидности, следует принять точку зрения разработчиков методики о том, что конечный результат, киллинговый эффект нейтрофилов более информативно описывает коэффрициент микробицидности (КМ) [12], который исчисляется путем деления значения стимулированного НСТ-теста на значение спонтанного НСТ-теста. Ме $\mathrm{kм} \mathrm{конто}=$ 1,40 у. ед. $\left[Q_{0,25}=1,33\right.$ у. ед.; $Q_{0,75}=1,45$ у. ед.], $M i n-1,26$ у. ед., Max - 1,47 у. ед.
Спустя 2 мин после алгогенного воздействия КМ статистически значимо отличался от контрольных значений (возрастал): $\mathrm{Me}_{\mathrm{Kм}}=1,72$ у. ед. $(p<0,001)\left[\mathrm{Q}_{0,25}=\right.$ 1,68 у. ед.; $Q_{0,75}=1,80$ у. ед.], Min - 1,63 у. ед., Max - 2,19 у. ед.

В течение первого часа эксперимента КМ снижался, однако не достигал контрольных значений, сохранялась тенденция его превалирования над КМ контрольной группы животных: $\mathrm{Me}_{\mathrm{kм}}=1,49$ у. ед. $\left[\mathrm{Q}_{0,25}=1,44\right.$ у. ед.; $Q_{0,75}=1,51$ у. ед.], Min - 1,32 у. ед., Мax - 1,53 у. ед.

К концу эксперимента КМ уже не имел статистически значимого отличия от контрольных значений: $\mathrm{Me}_{\mathrm{kм}}=$ 1,34 у. ед. $\left[Q_{0,25}=1,30\right.$ у. ед.; $Q_{0,75}=1,41$ у. ед.], $M i n-1,28$ у. ед., Мax $-1,47$ у. ед. (рис. 3).

\section{ОБСУЖДЕНИЕ РЕЗУЛЬТАТОВ}

Построение теоретических основ влияния острой соматической боли на фагоцитарную активность

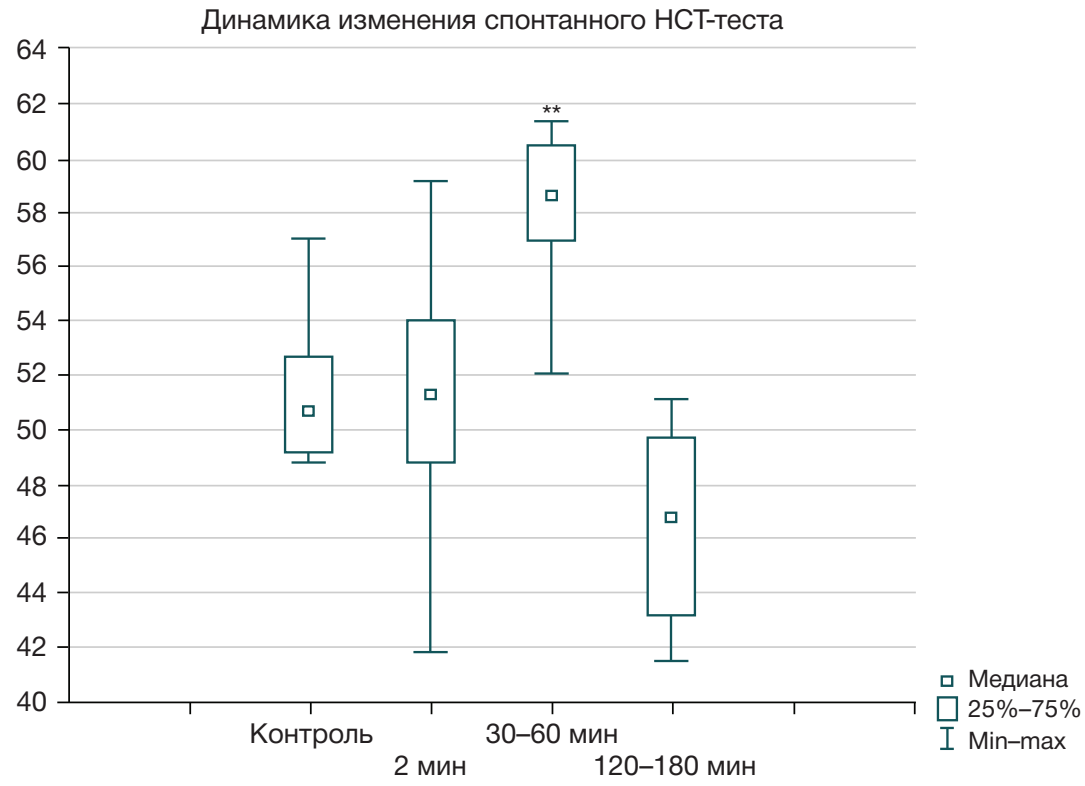

Рис. 1. Динамика изменения спонтанного НСТ-теста новорожденных крыс до и после болевого воздействия. ** — статистически значимые изменения по сравнению с контрольной группой $(p \leq 0,05)$

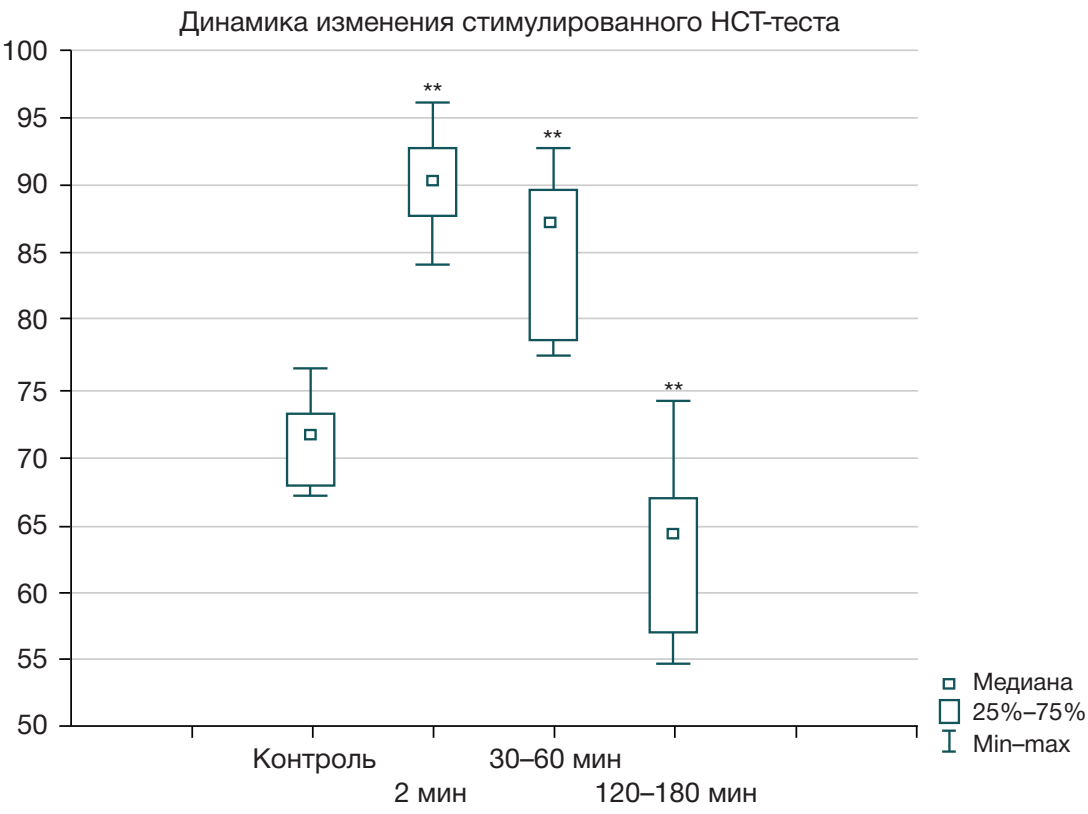

Рис. 2. Динамика изменения стимулированного НСТ-теста новорожденных крыс до и после болевого воздействия. ** — статистически значимые изменения по сравнению с контрольной группой ( $p \leq 0,05)$ 
нейтрофилов возможно только в контексте нейроиммунно-эндокринных взаимоотношений. Сегодня ни у кого не возникает сомнения в динамическом единстве механизмов нейрогенной, эндокринной и иммунной природы в поддержании внутреннего гомеостаза целостного организма. Патогенез боли, по крайней мере, его инициальный фрагмент аналогичен стрессу. В основе стресса не всегда боль, но острая боль - это всегда стресс, а потому в ответ на алгогенное раздражение выделяются гормоны стресса и прежде всего катехоламины. На модели, используемой нами, ранее было показано, что уже через 2 мин после нанесения болевого стимула на периферии обнаруживается увеличение содержания адреналина и норадреналина, соотношение которых зависит от возраста животных [12].

Электрофизиологический анализ показал, что раздражение ноцицепторов и передача возбуждения по восходящим путям при этом приводят к активации структур мозга, обеспечивающих контроль вегетативных функций и в первую очередь гипоталамуса, совпадают с активацией нейтрофильных гранулоцитов [13].

Помимо нейрогенного норадреналина в кровь из мозгового вещества надпочечников поступают адреналин и норадреналин. Они находят свои мишени, и события развиваются по классическим канонам стресса. Одним из объектов воздействия являются нейтрофилы, они экспрессируют как $\alpha$-, так и $\beta$-адренорецепторы [14], что было подтверждено позднее [15]. Как следствие, в нашей работе мы наблюдали увеличение фагоцитарной активности к первому часу эксперимента (спонтанный НСТтест), а при стимуляции — ко второй минуте после болевого воздействия (стимулированный НСТ-тест). Но уже к концу эксперимента фагоцитарная активность восстанавливается до исходных значений. В основе наблюдаемого снижения лежит активация $\beta$-адренорецепторов нейтрофилов [16]. Следует также учесть, что стресс сопровождается повышением продукции глюкокортикоидов, которые подавляют функциональную активность нейтрофилов [17].

Результат определения КМ свидетельствует о том, что нейтрофилы новорожденных крыс обладают киллинговой активностью $[11,18]$.
Установленные фракты активации спонтанного и стимулированного НСТ-тестов, а также повышение киллинговой активности нейтрофилов в ответ на болевое раздражение на первый взгляд вступают в противоречие с достаточно устоявшимся представлением о функциональной незрелости фагоцитов новорожденных.

Одной из возможных версий объяснения вскрытой закономерности является признание наиболее рано формирующейся способности продуцировать супероксидный радикал [19] на фоне редуцированных защитных функций нейтрофилов [20].

В период новорожденности идет активная колонизация микрофлорой организма ребенка, его кожных покровов, слизистых оболочек, органов желудочно-кишечного тракта, легких, мочеполовой системы. Процесс этот весьма интенсивен и скоротечен. Несмотря на то что факт колонизации стал хрестоматийным, его продолжают освещать в научной литуратуре в новых ракурсах [21-23]. Неизменной остается лишь точка зрения о том, что интенсивная антигенная нагрузка не может не мобилизовать факторы резистентности организма, с учетом того, что механизмы адаптивного иммунитета к моменту рождения еще не развиты. Следует согласиться: фракторы врожденного иммунитета и среди них нейтросрилы, как наиболее лабильные клетки, оперативно обеспечивающие первую линию защиты в период новорожденности, обретают ключевую роль. Открытие феномена бактериальной транслокации лишь подтверждает этот тезис [24].

Таким образом, система врожденного иммунитета новорожденных, с одной стороны, испытывает стимуляцию со стороны микробной колонизации, а с другой - это фон, на котором развертываются реакции, в частности нейтрофилов, на стимулы неантигенной природы, в нашем случае на острое алгогенное воздействие.

\section{ВЫВОДЫ}

1. У новорожденных крыс в ответ на острое алгогенное раздражение активируется и возрастает киллинговая активность нейтрофилов. 2. Реакции антимикробной защиты у нейтрофилов, наблюдаемые у новорожденных

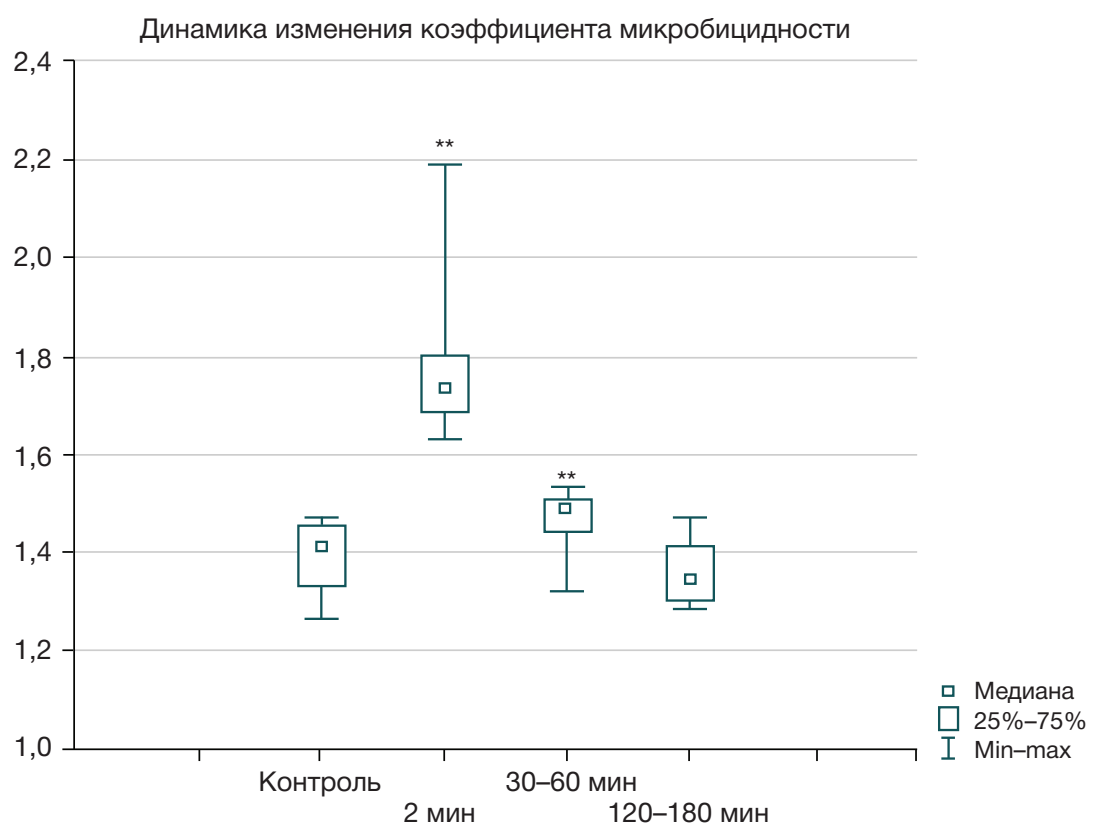

Рис. 3. Динамика изменения КМ новорожденных крыс до и после болевого воздействия. *夫 — статистически значимые изменения по сравнению с контрольной группой $(p \leq 0,05)$ 
крыс в ответ на краткосрочную острую болевую стимуляцию, непродолжительны и быстро истощаются. 3. Проведенные исследования расширяют представления о реакции метаболической активности нейтрофилов в ответ на острую боль у новорожденных. Результаты исследования могут быть использованы для дальнейшего изучения боли, адекватной оценки изменения параметров в онтогенезе и профилактики ее негативных последствий.

\section{Литература}

1. Гаркави Л. Х., Уколова М. А., Квакина Е. Б. Закономерность развития качественно отличающихся общих неспецисических адаптационных реакций организма. Научное открытие № 158 от 3.10.1969.

2. Шилова Ю. А., Шилов Д. Ю., Шилов Ю. И. Влияние стресса на активность лейкоцитов перисерической крови. Успехи современного естествознания. 2010; (7): 54-55.

3. Zhevago NA, Samoilova KA, Obolenskaya KD. The regulatory effect of polychromatic (visible and infrared) light on human humoral immunity. Photochemical \& Photobiological Sciences. 2004; 3 (1): 102-8.

4. Огнева О. И., Осиков М. В., Гизингер О. А., Федосов А. А. Механизм изменения иммунного статуса при экспериментальном десинхронозе в условиях светодиодного освещения. Современные проблемы науки и образования. 2015; (3): 184

5. Зюзя Е. В., Калуцкий П. В., Иванов А. В. Влияние сочетанного применения кровезаменителя перфторан и антибиотика цефатаксим на состояние иммунологических показатей периферической крови в условиях моделирования инфицированной раны и воздействия на организм постоянного магнитного поля. Вестник новых медицинских технологий. Электронное издание. 2013; (1): 80.

6. Акперов Э. К., Цыган В. Н., Степанов А. В. Состояние неспецифической резистентности у лиц, злоупотребляющих наркотическими веществами. Психосармакология и биологическая наркология. 2005; 5 (2): 963-5.

7. Базарин К. П., Савченко А. А., Ковалев В. Н., Лазаренко Н. А., Ландёнок А. В. Нейросетевое моделирование влияния факторов спортивной деятельности на функциональную активность нейтрофилов крови у квалисицированных спортсменов. Acta Biomedica Scientifica. 2017; 2 (114): 62-8.

8. Алексеева Н. С. Механизмы изменения фагоцитарной активности лейкоцитов при острой висцеральной боли [диссертация]. Ростов-на-Дону, 2008.

9. Абрамова М. В. Факторы врожденного иммунитета у самок крыс и их потомства при нормальных родах и болевой стимуляции [диссертация]. Ростов-на-Дону, 2019.

10. Овсянников В. Г. Очерки патофизиологии боли. Ростов-наДону: Цветная печать, 2003; 148 с.

11. Киселева Е. П., Полевщиков А. В. Метод автоматизированного учета НСТ-теста. Клиническая лабораторная диагностика. 1994; (4): 27-9.

12. Зайнаб А. М. Возрастные особенности моноаминергической реакции при острой боли [диссертация]. Ростов-на-Дону: 1995.

\section{References}

1. Garkavi LKh, Ukolova MA, Kvakina EB. Zakonomernost' razvitiya kachestvenno otlichayushchikhsya obshchikh nespetsificheskikh adaptatsionnykh reaktsiy organizma. Nauchnoe otkrytie № 158 ot 3.10.1969. Russian.

2. Shilova YuA, Shilov DYu, Shilov Yul. Vliyanie stressa na aktivnost leykotsitov perifericheskoy krovi. Uspekhi sovremennogo estestvoznaniya. 2010; (7): 54-5. Russian.

3. Zhevago NA, Samoilova KA, Obolenskaya KD. The regulatory effect of polychromatic (visible and infrared) light on human humoral immunity. Photochemical \& Photobiological Sciences. 2004; 3 (1): 102-8.

4. Ogneva OI, Osikov MV, Gizinger OA, Fedosov AA. Mekhanizm izmeneniya immunnogo statusa pri eksperimental'nom
13. Степанова Е. С. Влияние переохлаждения на функциональную активность лейкоцитов [диссертация]. Сыктывкар, 2010.

14. Heumann D, Visher TL. Immunomodulation by alpha2macroglobulin and alpha2-macroglobulin proteinase complexes: the effect on the T lymphocyte response. Eur J Immunol. 1988; (18): 755

15. Nicholls AJ, Wen Wen S, Hall P, Hickey MJ, Wong CHY. Activation of the sympathetic nervous system modulates neutrophil function. J Leukoc Biol. 2018; (103): 295-309.

16. Качина И. И., Шилов Д. Ю., Шилов Ю. И. Влияние агониста бета-адренорецепторов гексопреналина сульсата in vitro на фагоцитарную активность нейтрофилов периферической крови здоровых людей. Международный журнал прикладных и фундаментальных исследований. 2012; (1): 72-3.

17. Колесникова Н. В., Нестерова И. В., Чудилова Г. А. Ранние и отдаленные эффекты влияния экзогенного гидрокортизона на систему нейтросильных гранулоцитов лабораторных мышей. Гематология и трансфузиология. 1999; 44 (5): $36-40$.

18. Зинкин В. Ю., Годков М. А. Способ количественной оценки кислородзависимого метаболизма нейтрофильных гранулоцитов человека. Клиническая лабораторная диагностика. 2004; (8): 26-9.

19. Чиркин А. А. Биохимия с основами генной инженерии: учеб. пособие. Витебск: УО «ВГУ им. П. М. Машерова», 2010; 182 с.

20. Клименко Н. А., Шелест М. А. Функциональная активность нейтрофилов периферической крови при хроническом бронхите. Научные ведомости Белгородского государственного университета. Серия: Медицина. Фармация. 2013; 11 (154); Выпуск 22: 129-131.

21. Желнина Т. П., Брежнева Н. И., Осяев Н. Ю. Анализ структурь микрофрлоры новорожденных. Инфекция и иммунитет. 2016 6 (3): 26.

22. Беляева И. А., Бомбардирова Е. П., Митиш М. Д., Потехина Т. В., Харитонова Н. А. Онтогенез и дизонтогенез микробиоть кишечника у детей раннего возраста: триггерный механизм нарушений детского здоровья. Вопросы современной педиатрии. 2017; 16 (1): 29-38.

23. Николаева И. В., Царегородцев А. Д., Шайхиева Г. С Формирование кишечной микробиоты ребенка и факторы, влияющие на этот процесс. Российский вестник перинатологии и педиатрии. 2018; 63 (3): 13-8.

24. Никитенко Н. И., Захаров В. В., Бородин А. В. Роль транслокации бактерий В патогенезе хирургической инфекции. Хирургия. 2001; (2): 63-6. desinkhronoze $v$ usloviyakh svetodiodnogo osveshcheniya. Sovremennye problemy nauki i obrazovaniya. 2015; (3): 184. Russian.

5. Zyuzya EV, Kalutskiy PV, Ivanov AV. Vliyanie sochetannogo primeneniya krovezamenitelya perftoran i antibiotika tsefataksim na sostoyanie immunologicheskikh pokazatey perifericheskoy krovi $\vee$ usloviyakh modelirovaniya infitsirovannoy rany i vozdeystviya na organizm postoyannogo magnitnogo polya. Vestnik novykh meditsinskikh tekhnologiy. Elektronnoe izdanie. 2013; (1): 80. Russian.

6. Akperov EK, Tsygan VN, Stepanov AV. Sostoyanie nespetsificheskoy rezistentnosti u lits, zloupotreblyayushchikh narkoticheskimi veshchestvami. Psikhofarmakologiya 
biologicheskaya narkologiya. 2005; 5 (2): 963-5. Russian.

7. Bazarin KP, Savchenko AA, Kovalev VN, Lazarenko NA, LandenokAV. Neyrosetevoe modelirovanie vliyaniya faktorov sportivnoy deyatel'nosti na funktsional'nuyu aktivnost' neytrofilov krovi u kvalifitsirovannykh sportsmenov. Acta Biomedica Scientifica. 2017; 2 (114): 62-8. Russian.

8. Alekseeva NS. Mekhanizmy izmeneniya fagotsitarnoy aktivnost leykotsitov pri ostroy vistseral'noy boli [dissertatsiya]. Rostov-naDonu, 2008. Russian.

9. Abramova MV. Faktory vrozhdennogo immuniteta u samok krys i ikh potomstva pri normal'nykh rodakh i bolevoy stimulyatsi [dissertatsiya]. Rostov-na-Donu, 2019. Russian.

10. Ovsyannikov VG. Ocherki patofiziologii boli. Rostov-na-Donu: Tsvetnaya pechat', 2003; 148 s. Russian.

11. Kiseleva EP, Polevshchikov AV. Metod avtomatizirovannogo ucheta NST-testa. Klinicheskaya laboratornaya diagnostika. 1994; (4): 27-9. Russian.

12. Zajnab AM. Vozrastnye osobennosti monoaminergicheskoj reakcil pri ostroj boli [dissertacija]. Rostov-na-Donu, 1995. Russian.

13. Stepanova ES. Vlijanie pereohlazhdenija na funkcional'nuju aktivnost' lejkocitov [dissertacija]. Syktyvkar, 2010. Russian.

14. Heumann D, Visher TL. Immunomodulation by alpha2macroglobulin and alpha2-macroglobulin proteinase complexes: the effect on the T lymphocyte response. Eur J Immunol. 1988; (18): 755

15. Nicholls AJ, Wen Wen S, Hall P, Hickey MJ, Wong CHY. Activation of the sympathetic nervous system modulates neutrophil function. J Leukoc Biol. 2018; (103): 295-309.

16. Kachina II, Shilov DYu, Shilov Yul. Vlijanie agonista betaadrenoreceptorov geksoprenalina sul'fata in vitro na fagocitarnuju aktivnost' nejtrofilov perifericheskoj krovi zdorovyh ljudej. Mezhdunarodnyj zhurnal prikladnyh i fundamental'nyh issledovanij. 2012; (1): 72-3. Russian.

17. Kolesnikova NV, Nesterova IV, Chudilova GA. Rannie i otdalennye jeffekty vlijanija jekzogennogo gidrokortizona na sistemu nejtrofil'nyh granulocitov laboratornyh myshej. Gematologija i transfuziologija. 1999; 44 (5): 36-40. Russian.

18. Zinkin VYu, Godkov MA. Sposob kolichestvennoy otsenki kislorodzavisimogo metabolizma neytrofil'nykh granulotsitov cheloveka. Klinicheskaya laboratornaya diagnostika. 2004; (8): 26-9. Russian.

19. Chirkin AA. Biokhimiya s osnovami gennoy inzhenerii: ucheb. posobie. Vitebsk: UO "VGU im. P. M. Masherova", 2010; 182 s. Russian.

20. Klimenko NA, Shelest MA. Funktsional'naya aktivnost' neytrofilov perifericheskoy krovi pri khronicheskom bronkhite. Nauchnye vedomosti Belgorodskogo gosudarstvennogo universiteta. Seriya: Meditsina. Farmatsiya. 2013; 11 (154); Vypusk 22: 129-31. Russian.

21. Zhelnina TP, Brezhneva NI, Osyaev NYu. Analiz struktury mikroflory novorozhdennykh. Infektsiya i immunitet. 2016; 6 (3): 26. Russian.

22. Belyaeva IA, Bombardirova EP, Mitish MD, Potekhina TV, Kharitonova NA. Ontogenez i dizontogenez mikrobioty kishechnika u detey rannego vozrasta: triggernyy mekhanizm narusheniy detskogo zdorov'ya. Voprosy sovremennoy pediatrii. 2017; 16 (1): 29-38. Russian.

23. Nikolaeva IV, Tsaregorodtsev AD, Shaykhieva GS. Formirovanie kishechnoy mikrobioty rebenka i faktory, vliyayushchie na etot protsess. Rossiyskiy vestnik perinatologii i pediatrii. 2018; 63 (3): 13-8. Russian.

24. Nikitenko NI, Zakharov W, Borodin AV. Rol' translokatsii bakteriy v patogeneze khirurgicheskoy infektsii. Khirurgiya. 2001; (2): 63-6. Russian. 